\title{
The Delay and Change of the Postmaterialist Values in Korea
}

\author{
Yang, Haeman
}

\begin{abstract}
Although Inglehart argues that preference of post-materialist value is likely to increase in Europe, existing studies have shown that preference for post-materialist value is not likely to increase in South Korea. However, the cause still remains ambiguous because existing studies have presented partial explanations using cross-sectional analysis as well as limited evidence. Therefore, this study focuses on the key variable which is the psychological economic insecurity. Based on time-series analysis, this study tests that how the psychological economic insecurity affects the change of value preference in South Koreans. The test result shows that psychological economic insecurity has an influence on the change of value preference depending on the economic situation. Concretely, the psychological economic insecurity does not have a significant effect on the change of the value preference during the economic boom. On the other hand, the psychological economic insecurity has a significant effect on the change of the value preference in an economic recession. These results imply that the increase of post-materialist value preference will be delayed.
\end{abstract}

Keywords - Changes of value priorities, Dissatisfaction with the household economy, Economic insecurity.

\section{INTRODUCTION}

The debate about postmaterialist value first came to be deeply related to various phenomena that appeared in the advanced industrial countries of the West in the late 1970s and early 1980s. At this time, advanced industrial countries of the West were equipped with diverse welfare systems based on high level economic growth and provided the material abundance and stability to the majority of the members of society. At the same time, the issue of values such as 'legalization of divorce', 'tolerance for homosexuality', 'gender equality', and 'environment' began to rise on the surface of the water. Also during this period, 'Green Party' appeared for the first time.

Thus, Ingehart(1971) focuses on various phenomena that appear in advanced industrial countries of the West, suggested a postmaterialist values in order to predict and explain the possibility of the class structure (Inglehart, 1971). Afterwards, postmaterialist values have become a factor explaining various phenomena such as the improvement of democracy, the change of society, and the change of politics as the scope of application is expanded.

If so, what are the postmaterialist values? The way to define the postmaterialism is somewhat different depending on the researcher, but usually means pursuing spiritual elements or

Yang, Haeman / Department of Political Science, Sogang University, Seoul, South Korea.Email: goaks123@naver.com elements over physical elements(Sung and Park, 1999). And the postmaterialism is closely related to the economic wealth and it is known that the change of the priority is shown through the generations.

In particular, older generations who have experienced poverty and agitation in their socialization process have a higher preference for materialistic values such as economic stability and order formation, younger generations who have experienced economic wealth and stability during socialization process have a higher preference for postmaterialist values such as quality of life, freedom of expression, and political participation(Park and Kang, 2012). Regarding a certain pattern of change in value priority across generations, Inglehart called "Theory of Intergenerational Value Change" (Inglehart, 1997).

The 'Theory of Intergenerational Value Change' has some theoretical implications. First, as long as economic prosperity and social stability continue, the younger generation will tend to prefer postmaterialist values over older generations. Second, the change in value priority at the aggregate level occurs when younger generation who prefers postmaterialist values replace an older generation who prefers materialistic values. Third, the change of value priority at the aggregate level takes place over a long period of time because it is done through generation replacement. Fourth, changes of value priorities lead to changes in various areas such as politics, society, and culture. Fifth, the social change caused by changes of value priorities is largely democratic-friendly(Inglehart, 1971; Inglehart, 1997 ;Inglehart and Welzel, 2011).

The results of various empirical analyzes conducted on advanced industrial countries in the West show a tendency to be consistent with the implications of the Theory of Intergenerational Value Change. First, at the aggregate-level, the prevalence of postmaterialist values tended to increase in most of the analyzed countries. Second, changes at the individual level support the changes at the aggregate level. Younger generations prefer the postmaterialist values compared to older generations, and the newly inflowed generations are also more favored postmaterialist values. Third, those who favored postmaterialist values were found to prefer more critical, more direct, and more democratic-friendly behaviors than those who did not(Abramson and Inglehart 1992; Inglehart and Abramson 1994; Inglehart 1971; Inglegart 1997; Inglehart and Welzel, 2011).

However, the study of postmaterialist values, which have been discussed and verified only in the advanced industrial countries of the West, has come to a new phase. Because the emergence of East Asian newly Industrializing countries and the worldwide spread of democracy, the applicability of the 'Theory 
of Intergenerational Value Change' has expanded from Western to non-Western countries. For example, South Korea, one of the East Asian newly Industrializing countries, has experienced rapid economic growth for the last 30 years and has provided a certain level of material abundance and stability to the majority of its members. In addition, since 1987, the democratic system based on procedural justice has been established. Therefore, it can be predicted that the changing aspect of value priorities in South Korea can be fully satisfied with the theoretical expectation implied by the 'Theory of Intergenerational Value Change'.

However, when we look at the results of various empirical analyzes conducted on South Korea, the changes at the individual level and the changes at the aggregate level are contradictory to each other. First, looking at changes at the individual level, younger generations tend to prefer postmaterialist values over older generations. Also, those who prefer postmaterialist values prefer the democratic-friendly behaviors and attitudes than those who do not prefer materialist values(Kim and Lee, 2006; Ma, Chang, and Kim 1997; Kang and Park, 2011; Auh, 2004). However, unlike the theoretical expectation that the preference for postmaterialist values will continue to increase, changes at the aggregate level are being delayed or declining at low. Specifically, according to the World Values Survey conducted five times in total from 1990 to 2010, the preference for postmaterialist values in the 1990, 1996, and 2001 surveys was delayed at a certain level. And the preference for postmaterialist values in the 2005 and 2010 surveys was lower than the previous survey

Why is change at the aggregate level lagging and even declining, even though South Korea is experiencing changes at the individual level? In response to these questions, previous studies have provided roughly three factors. The first factor is cultural specificity(Sung and Park, 1999; Bomhoff and Gu, 2012). East Asian countries have their own unique cultural characteristics different from Western countries. So, apply 'Theory of Intergenerational Value Change' derived from the Western culture to East Asian countries is somewhat unreasonable. And the pattern of change in value priorities is also different. The second factor is short-term or micro-economic problems(Flanagan 1982; Clarke, Dutt 1991; Clarke et al 1999). South Korea, which has experienced rapid economic growth, has been continuously exposed to economic problems such as the economic recession since the 1997 IMF economic crisis(Kim and Lee, 2006; Park and Kang, 2012). This suggests that the increase in preference for postmaterialist values is be delayed. The third factor is insufficient of the welfare system(Cho, 2015). The welfare system in South Korea was introduced as a part of the neo-liberal policy to start in earnest after the IMF economic crisis(Son, 2004). Therefore, the welfare system was inevitably poor, and the insufficient of the welfare system delayed the increase in preference for the postmaterialist value through insecurity.

Nevertheless, the gap between theoretical expectation implied by 'Theory of Intergenerational Value Change' and empirical facts in Korea remains vague. First, the study pointing to the cultural peculiarities emphasizes the difference between the West and East Asia, does not explain the changing patterns at the individual level that are consistent with the theoretical expectations. Likewise, the studies pointing to short-term economic problems only rely on the logical basis of reasoning for changes in survey time, generation, and value composition, thus presenting only evidence at a partial level. Finally, research that points to the insufficient of the welfare system depends on cross-sectional analysis. So it is not possible to explain the phenomenon in which the preference for postmaterialist values are lower after the introduction of the welfare system than before the introduction of the welfare system.

Therefore based on the results of previous studies, this study attempts to reexamine the gap between the theoretical expectation and the reality of Korea in a more comprehensive way. While the value priorities of Koreans are changing at the individual level, changes at the aggregate level are delayed. This is because the social and economic development path of the West, which is based on the "theory of value change between generations," and the social and economic development path of Korea are generally inconsistent. Hence this study focuses on the economic structure of South Korea different from that of the West, and tracks the psychological economic factors such as 'economic insecurity' in addition to the objective economic factors, which may affect the change in the value preference of Koreans. And through the World Values Survey, which was conducted five times from 1990 to 2010, this study examines the relationship between economic insecurity and preferences for postmaterialist values with Time Series Analysis. In addition, a comprehensive review of change at the individual level and changes at the aggregate level will provide a more balanced view of changes in the value priorities of Koreans. Finally, this comprehensive analysis provides a prospect on changes in the value priorities of Koreans.

\section{DATA AND MEASUREMENT OF VARIABLES}

This study used the World Values Survey, conducted six times from 1980 to 2010, in order to examine the relationship between 'anxiety about the economy' and changes in the value priorities of Koreans. The dependent variable is the postmaterialist value measured by the 5-point scale through the 12-item index, 0 point to 1 point for materialist 2 points for mixed-materialist 3 points for mixed-postmaterialist 4 points to 5 point for postmaterialist Respectively. Independent variables are "economic insecurity" To measure this, "dissatisfaction with the household economy" and "number of children" are used. The 'dissatisfaction with the household economy' was originally composed of 10 points scale, and it was recomposed to 5 point scale for convenience of analysis. In the case of 'number of children', $0,1,2$, and 3 or more people were composed considering the proportion of the sample. In addition, various variables pointed out by previous studies such as income level, education level, generation, age and ideology are additionally considered.

\section{EMPIRICAL ANALISYS}

According to the "Theory of Intergenerational Value Change", the change of value priority in Korea will be accompanied by a decrease in the proportion of materialist values and a rise in the proportion of mixed and postmaterialist 
values.

However, Figure 1-1 shows that the proportion of postmaterialistic values is delaying or declining, unlike the theoretical expectations. Also, materialistic values are continuously decreasing and mixed types are continuously increasing, which means that the reduction of materialist value is not conducive to postmaterialis values.

For the more detailed review, classified the mixed types into mixed-materialists and mixed-postmaterialists, tracked the ratio of each value in a time-series trend. As you can see in Figure $1-2$, the mixed-materialist is steadily increasing, and the mixed-postmaterialist is still delaying. This confirms that the reduction of materialistic value leads to an increase of mixed-materialist, but not to the increase of mixed-postmaterialist or postmaterialist value.

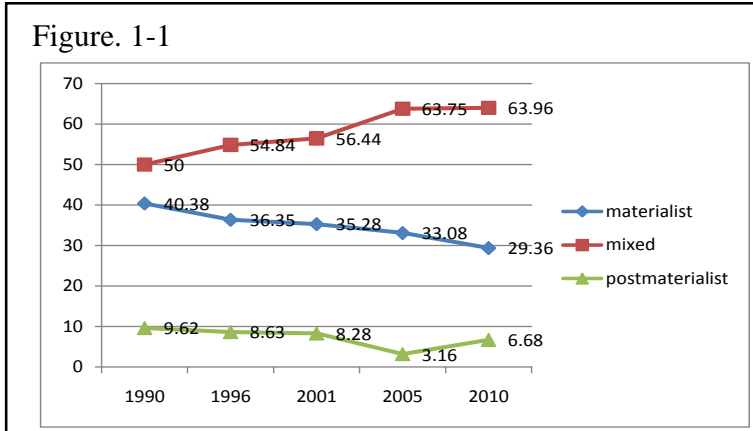

\section{Figure. 1-2}

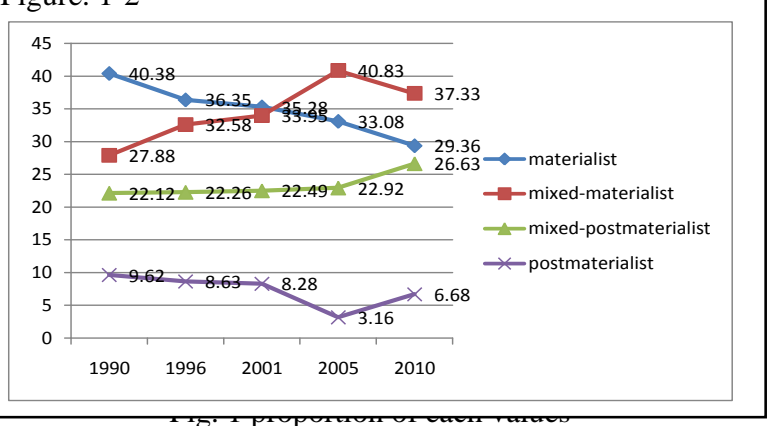

Why is South Korea stagnating or declining postmaterialistic values, even though materialist values are decreasing? The reasons are in the economic development process and economic structure of South Korea.

South Korea has achieved industrialization through the control of development countries and the policies of labor oppression. So, economic abundance and stability during economic development was not enough to spread the postmaterialist values at the aggregate level. Also, the social security system was dependent on the full employment system and trickle down effect, not the welfare system, due to the economic structure centered on large companies. Therefore for
Koreans, "economic insecurity" is always inherent.

Since the IMF economic crisis, South Korea has induced a full range of neoliberal policies and has been undergoing a continuous economic recession. As a result, the full employment system and the trickle down effect, which have reduced the insecurity of Koreans, have collapsed. Actually, Gini coefficient, which indicates the actual economic polarization, has surged since the IMF economic crisis, and the youth unemployment rate also stood at about $8 \%$ between 2004 and 2016 (Statistics Korea). Thus, the decline in the postmaterialist values that have appeared since 2005 can be interpreted as a result of the 'economic insecurity' which had been inherent to the Koreans because of the economic conditions.

Table 1 below shows the results of the sequential logistic analysis of the change in value priorities. As you can see in <Model 1> Generation effect, which is the main factor explaining the 'theory of value change between generations', was found to exist only in the 40 's and 60' s when considered together with the age effect. Also, age effect has a significant effect on the change of the value priority even though the generation effect is controlled. The results of this analysis say that 'Theory of Intergenerational Value Change' is a limited application in Korea.

Next, educational level and ideology tendency were found to have a significant effect on the change of value priority as the results of previous studies. The higher the level of education, the higher the likelihood of preferring the postmaterialist value, and the more conservative the ideological propensity, the less likely it is to prefer the postmaterialist value.

Finally, 'economic insecurity' was confirmed to have a significant effect on the change of value priority as predicted in this study. Specifically, dissatisfaction with the household economy has reduced the likelihood of preferring postmaterialist values. Likewise, an increase in the number of children has reduced the likelihood of preferring a postmaterialist value. To further examine the effect of household economic satisfaction on the change in value priorities, we analyzed each period separately (Model 2 to Model 6). It shows that dissatisfaction with the household economy has a significant impact on changes in value priorities since 2005 (Model 5 to Model6). the case of the 2005, the likelihood of preferring a postmaterialist values declined by $4.5 \% \mathrm{p}$ when the level of dissatisfaction with the household economy shifted from 1 to 5 . And the case of the 2010, the likelihood of preferring a postmaterialist values declined by about $8 \% \mathrm{p}$ when the dissatisfaction with the household economy shifted from 1 to 5 . Considering that the influence of education is about $13 \% \mathrm{p}$, the influence of dissatisfaction on the household economy is not small. 
TABLE I: THE RESULTS OF THE SEQUENTIAL LOGISTIC ANALYSIS

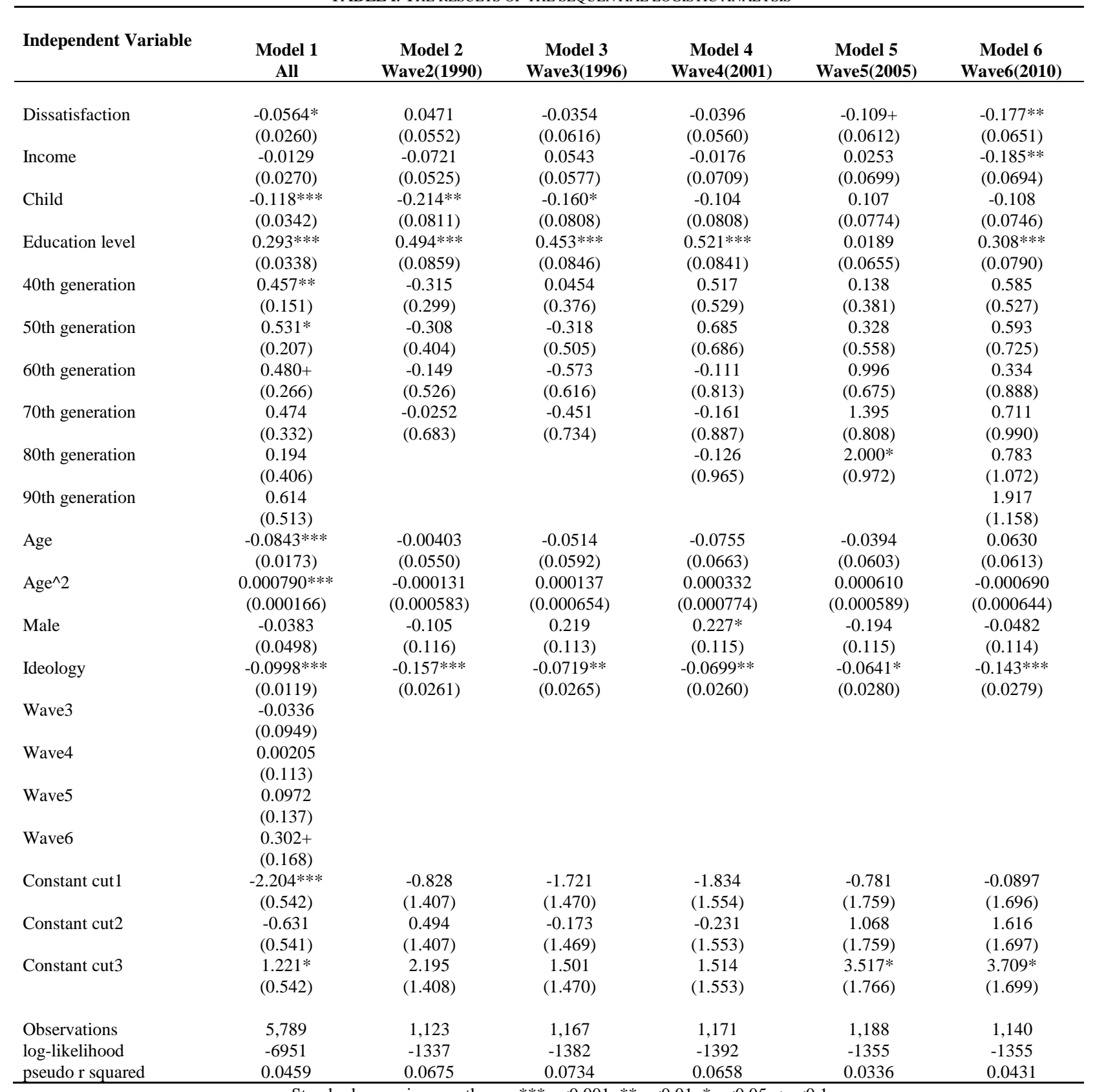

Standard errors in parentheses $* * * \mathrm{p}<0.001, * * \mathrm{p}<0.01, * \mathrm{p}<0.05,+\mathrm{p}<0.1$ 
Figure 2 depicts a time series relationship between dissatisfaction and change in value priorities in the household economy.

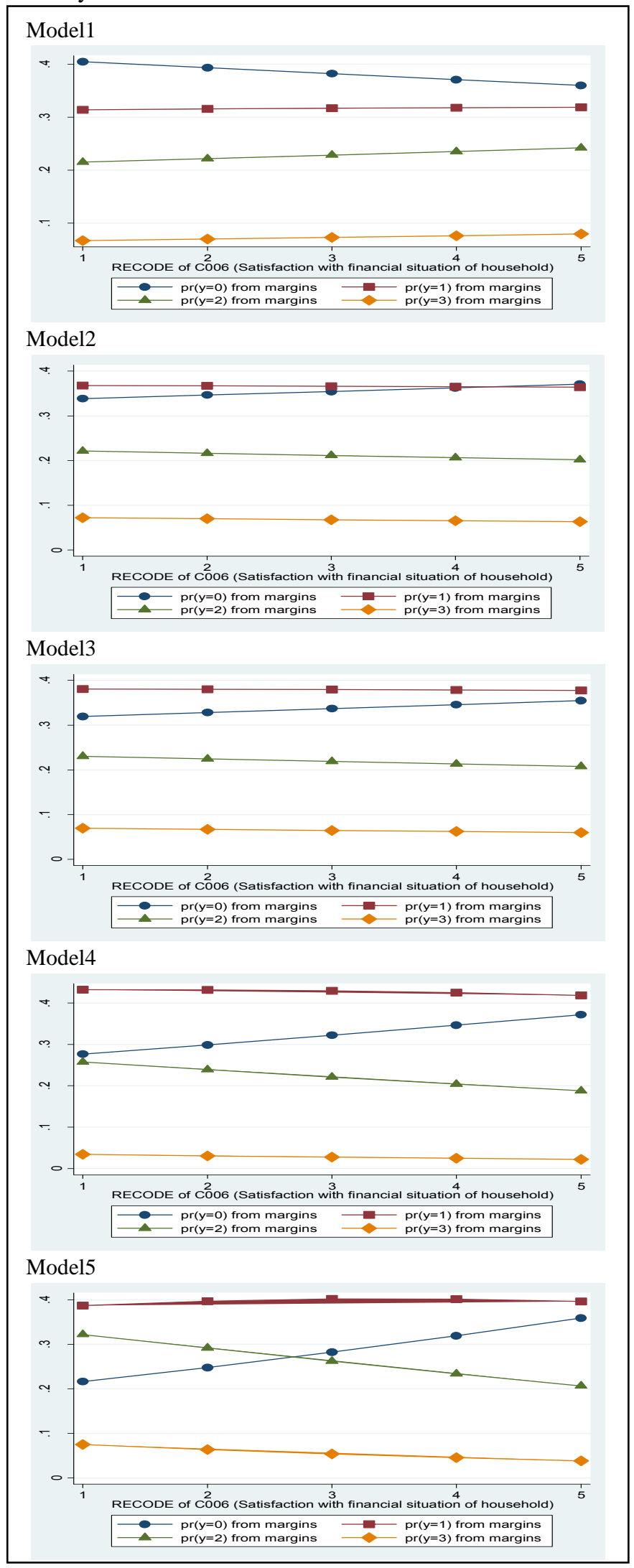

Fig. 2 time series relationship between dissatisfaction and each values
Certainly, the relationship between dissatisfaction with the household economy and the change in value priorities becomes clearer as a time-series trend continues. The results of this analysis show that 'economic insecurity' started to affect the change of value priority due to deteriorating economic conditions. In addition, decline in the impact of the education level since 2005 confirms this analysis.

\section{CONCLUSION}

So far, we have examined the delay and change of the postmaterialist values of Koreans. In sum, 'Theory of Intergenerational Value Change' is applied only partially, that the preference for postmaterialist values will increase with economic development. And, the economic stability felt by Koreans because of the economic development strategy and economic structure was not enough to spread the postmaterialist values at the aggregate level. In addition, due to the deterioration of the economic conditions after the IMF economic crisis, "economic insecurity" began to have a negative impact on the change in preference for postmaterialist values since 2005.

The results of this analysis make it possible to predict that preferences for postmaterialist values will not increase. Because the problem of economic polarization and unemployment is not likely to be solved easily, and the prospects for the economy are constantly dimming.

\section{REFERENCES}

[1] Abramson, Paul R., and Ronald Inglehart," Generational Replacement and Value Change in Eight West European Societies," British Journal of Political Science, 1992, 22 (02), pp. 183-228. https://doi.org/10.1017/S0007123400006335

[2] Bomhoff, Eduard J., and Mary M. Gu, "East Asia Remains Different a Comment on the Index of "self-Expression Values," by Inglehart and Welzel." Journal of Cross-Cultural Psychology, 2012, 43 (3), pp. 373-83. https://doi.org/10.1177/0022022111435096

[3] Clarke, Harold D, and Nitish Dutt, "Measuring Value Change in Western Industrialized Societies: The Impact of Unemployment." American Political Science Review, 1991, 85 (03), pp. 905-20. https://doi.org/10.2307/1963855

[4] Clarke, Harold D, Allan Kornberg, Chris McIntyre, Petra Bauer-Kaase, and Max Kaase, "The Effect of Economic Priorities on the Measurement of Value Change: New Experimental Evidence," American Political Science Review, 1999, 93 (03), pp. 637-47.

https://doi.org/10.2307/2585579

[5] Duch, Raymond M, and Michaell A. Taylor, "Postmaterialism and the Economic Condition," American Journal of Political Science, 1993, pp. 747-79.

https://doi.org/10.2307/2111573

[6] Flanagan, Scott C. "Measuring Value Change in Advanced Industrial Societies:" A Rejoinder to Inglehart", Comparative Political Studies, 1982, 15 (1), pp. 99. https://doi.org/10.1177/0010414082015001005

[7] Ho Chul Son, " Modern Korean Politics: Theory and History 1945-2003," Seoul: Social Review, 2004.

[8] Inglehart, Ronald, "The Silent Revolution in Europe: Intergenerational Change in Post-Industrial Societies," American Political Science Review, 1971, 65 (04), pp. 991-1017. https://doi.org/10.2307/1953494

[9] -Modernization and Postmodernization: Cultural, Economic, and Political Change in 43 Societies" Princeton, N.J: Princeton University Press, 1997.

[10] Inglehart, Ronald, and Paul R. Abramson, "Economic Security and Value Change," American Political Science Review, 1994, 88 (02), pp. 336-54. 
https://doi.org/10.2307/2944708

[11] Jae-Heung Park, and Soo-Taek Kang. "Intergenerational Change and Postmaterialism in Korea : Cohort Analysis," Korean Journal of Sociology, 2012, 46 (4) (2012/8), pp. 69-95.

[12] Khee Joong Seong, and Hyung Park, "Postmaterialism Truth or Fiction?" Korean Journal of Political Science, 1999, 7 (2), pp. 143-73.

[13] Seongkyung Cho, and In-Jin Yoon, "The International Comparison of Post-Materialism," Development and Society, 2015, 44 (3) (2015/12), pp. 495-533.

[14] Soo Taek Kang, and Jae Heung Park, "The Change in Korean Social Movements and the Post-Materialism," Oughtopia, 2011, 26 (3) (2011/12), pp. 5-38.

[15] Soo Young Auh, "Value Changes and Consolidation of Democracy in Korea: Comparison of Change in the Three Waves of Surveys-1990, 1996 and 2001," Korean Political Science Review, 2004, 38 (1) (2004/3), pp. 193-214.

[16] Wook Kim, and Rhee Beom Lee. "Post-Materialism and Democracy: A Comparison of Cultural Changes in Korea and Japan," Korean Party Studies Review, 2006, 5 (2) (2006/8), pp. 89-124. 